\title{
Synthesis of methylenebisamides using CC- or DCMT-activated DMSO
}

\author{
Qiang Wang ${ }^{1,2}$, Lili Sun ${ }^{1}$, Yu Jiang ${ }^{1}$ and Chunbao Li ${ }^{*}{ }^{1}$
}

\section{Full Research Paper}

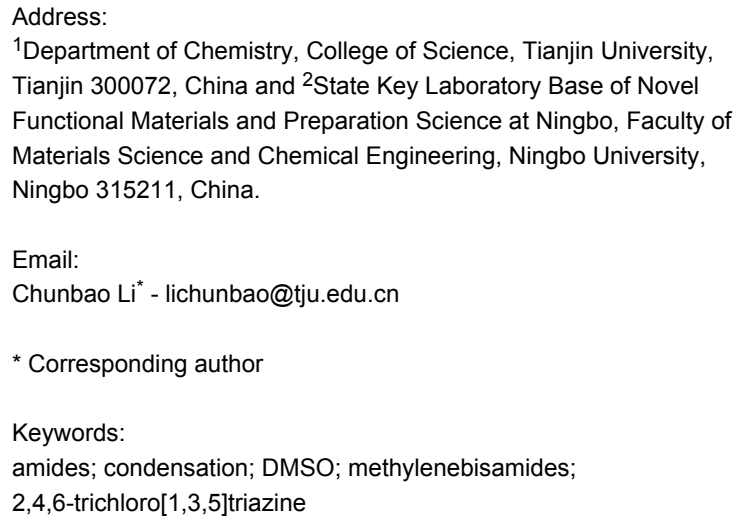

Beilstein Journal of Organic Chemistry 2008, 4, No. 51 doi:10.3762/bjoc. 4.51

Received: 28 October 2008

Accepted: 04 December 2008

Published: 15 December 2008

(C) 2008 Wang et al; licensee Beilstein-Institut.

License and terms: see end of document.

\begin{abstract}
Bisamides are key fragments for the introduction of gem-diaminoalkyl residues into retroinverso pseudopeptide derivatives and in the synthesis of peptidomimetic compounds. The literature methods for these types of compounds have certain drawbacks. In particular, when amides react with electrophile-activated DMSO, the yields are rather low. We have found new electrophiles, 2,4,6trichloro[1,3,5]triazine (CC) and 2,4-dichloro-6-methoxy[1,3,5]triazine (DCMT), which activate DMSO in the presence of amides to yield methylenebisamides in good to fair yields. The amides can be aromatic or aliphatic. The operation is simple and the reagents are inexpensive.
\end{abstract}

\section{Introduction}

Sulfoxides are activated by electrophiles to produce reactive sulfonium salts. These electrophiles include DCC [1,2], acetic anhydride [3], trifluoroacetic anhydride [4], acetyl chloride [5], phosphorus pentoxide [6], polyphosphoric acid [7], sulfuric acid and sulfur trioxide [6] etc. A few reactions such as the Pummerer reaction [8] and Swern oxidation [9] can be performed via the reactive sulfonium salts formed from DMSO and electrophiles.
The reactions of amides with DMSO in presence of electrophiles (sulfur trioxide, acetic anhydride, phosphorus pentoxide) give $N, N^{\prime}$-methylenebisamides and $N$-acylsulfilimines, but rather low yields of $N, N^{\prime}$-methylenebisamides (20\%) [6]. From our previous research on the chlorination [10] and etherification [11] of benzyl alcohols and from other references [12-14], we believe the reaction between 2,4,6-trichloro[1,3,5]triazine (cyanogen chloride, or $\mathrm{CC}$ ) and DMSO produces a reactive sulfonium salt intermediate. Therefore, it was of interest to 
study the reaction of nucleophilic reagents such as amides, alcohols, and phenols with DMSO activated by CC.

The amide moiety is an important constituent of many biologically significant compounds. Bisamides are of considerable interest in the synthesis of peptidomimetic compounds [15]. In particular, bisamides are key fragments for the introduction of gem-diaminoalkyl residues in retro-inverso pseudopeptide derivatives [16] by treating the corresponding amide with iodobenzene bistrifluoroacetate [17]. $N, N^{\prime}$-Methylenebisamides are usually prepared by the reactions of amides with aldehydes [18-20], hexamethylenetetramine [21] or activated DMSO [6], or by the reaction of nitriles with formaldehyde [22] or activated sulfoxides [23]. However, each method has certain limitations with regards to scope and reaction conditions, for example, longer reaction time [20], lower yield [6], purification problems [21,23] and drastic reaction conditions [19,22].

In this paper, we report the reaction of amides with DMSO activated by CC or 2,4-dichloro-6-methoxy[1,3,5]triazine (DCMT) [24].

\section{Results and Discussion}

Initially, we chose $\mathrm{CC}$ as the activation reagent and benzamide as a model substrate to optimize the reaction conditions (Scheme 1, Table 1). No product was observed when the reaction was carried out in $\mathrm{CH}_{3} \mathrm{CN}$ (Table 1, entry 1). The reaction proceeded in $\mathrm{CHCl}_{3}$, DMSO, EtOAc and toluene (Table 1, entries 2-5), but considerable amounts of undesired products were formed in $\mathrm{CHCl}_{3}$, DMSO and EtOAc (Table 1, entries

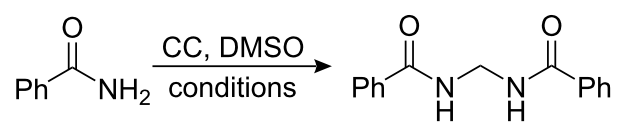

Scheme 1: Synthesis of $N, N^{\prime}$-methylenedibenzamide using CC-activated DMSO.

\begin{tabular}{|c|c|c|c|c|}
\hline Entry & Solvent & Temp $\left({ }^{\circ} \mathrm{C}\right)$ & $t(h)$ & Yield $(\%)^{b}$ \\
\hline 1 & $\mathrm{CH}_{3} \mathrm{CN}$ & RT & 24 & 0 \\
\hline 2 & $\mathrm{CHCl}_{3}$ & RT & 4 & $10^{c}$ \\
\hline 3 & DMSO & $\mathrm{RT}$ & 24 & 26 \\
\hline 4 & EtOAc & $\mathrm{RT}$ & 4 & 30 \\
\hline 5 & Toluene & RT & 4 & 70 \\
\hline 6 & Toluene & $\mathrm{RT}$ to 70 & 2 & $71^{d}$ \\
\hline
\end{tabular}

$\mathrm{a}_{1.0}$ equiv amide, 1.2 equiv $\mathrm{CC}, 7.0$ equiv dry $\mathrm{DMSO}$, dry toluene $(8.0 \mathrm{~mL})$. ${ }^{\text {b Isolated yield; ' }}{ }^{\mathrm{S}} \mathrm{S}, \mathrm{S}$-Dimethyl- $N$-benzoylsulfilimine $(40 \%$ yield $)$ as major product; dStirred for $30 \mathrm{~min}$ at $\mathrm{RT}$, then $70{ }^{\circ} \mathrm{C}$ for $1.5 \mathrm{~h}$.
$2-4)$. Better results were obtained when the reactions were performed in toluene (Table 1, entry 5). Encouraged by these results, we studied the effects of temperature on the reaction in toluene. Elevating the temperature to $70{ }^{\circ} \mathrm{C}$ resulted in an improved reaction rate. As for the influence of $\mathrm{CC}$ and DMSO dosage on the reaction, it was found that decreasing the amount of $\mathrm{CC}$ to 0.9 equiv resulted in reduced yield, while increasing the amount to 1.5 equiv did not make the reaction system complex and the yield was not notably different. Excess amount of DMSO (7.0 equiv) was used partially because of its ability to dissolve the amides.

After the optimization of the reaction conditions, various substrates were subjected to the conditions (Scheme 2, Table 2). The electronic effect of the substituents on aromatic rings was observed. For example, a strong electron-donating or electronwithdrawing group on the aromatic ring resulted in decreased reaction yields (Table 2 , entries 5,8 ), while a substituent on the para-position or meta-position led to a moderate yield (Table 2, entries 4,7$)$. The effect of substituents on the reaction rate was not remarkable. However, the method was not efficient for the aliphatic amides: considerable amounts of by-products were formed, probably due to the greater nucleophilicity of the aliphatic amides.

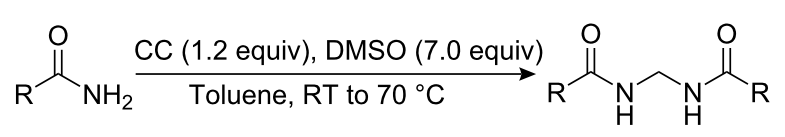

Scheme 2: Synthesis of $N, N^{\prime}-$-methylenebisamide using CC-activated DMSO.

\begin{tabular}{|c|c|c|c|}
\hline Entry & $\mathrm{R}$ & $t(h)$ & Yield $(\%)^{b}$ \\
\hline 1 & $\mathrm{Ph}$ & 2 & 71 \\
\hline 2 & $4-\mathrm{CH}_{3} \mathrm{C}_{6} \mathrm{H}_{4}$ & 4 & 86 \\
\hline 3 & 4- $\mathrm{MeOC}_{6} \mathrm{H}_{4}$ & 2 & 72 \\
\hline 4 & $2-\mathrm{MeOC}_{6} \mathrm{H}_{4}$ & 1.5 & 67 \\
\hline 5 & $3,5-(\mathrm{MeO})_{2} \mathrm{C}_{6} \mathrm{H}_{3}$ & 4 & 30 \\
\hline 6 & $4-\mathrm{ClC}_{6} \mathrm{H}_{4}$ & 5 & 74 \\
\hline 7 & $3-\mathrm{ClC}_{6} \mathrm{H}_{4}$ & 4 & 60 \\
\hline 8 & $4-\mathrm{NO}_{2} \mathrm{C}_{6} \mathrm{H}_{4}$ & 4 & 20 \\
\hline 9 & $\mathrm{PhCH}=\mathrm{CH}$ & 3 & 50 \\
\hline 10 & $\mathrm{PhCH}_{2}$ & - & $-^{\mathrm{c}}$ \\
\hline 11 & $\mathrm{PhOCH}_{2}$ & - & $-^{c}$ \\
\hline 12 & $\left(\mathrm{CH}_{3}\right)_{3} \mathrm{C}$ & - & $-^{\mathrm{c}}$ \\
\hline 13 & $\mathrm{CH}_{3}\left(\mathrm{CH}_{2}\right)_{5} \mathrm{CH}_{2}$ & - & $-^{c}$ \\
\hline
\end{tabular}

$\mathrm{a}_{1.0}$ equiv amide, 1.2 equiv $\mathrm{CC}, 7.0$ equiv dry DMSO, dry toluene (8.0

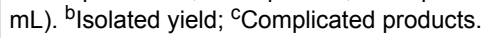


In order to improve the yield of aliphatic amides, less active DCMT was used as activating reagent instead of CC. We also optimized the reaction conditions using benzamide as a benchmark (Scheme 3, Table 3). The reaction did not proceed when low boiling solvents such as $\mathrm{CH}_{3} \mathrm{CN}, \mathrm{CHCl}_{3}$ and $\mathrm{ClCH}_{2} \mathrm{CH}_{2} \mathrm{Cl}$ were used (Table 3, entries 1-3). It was performed efficiently in high boiling solvents (1,4-dioxane, xylene and DMSO) (Table 3 , entries 4-6). The results indicate that the effect of temperature on the reaction is remarkable. The electronic effect of the substituents on aromatic rings was similar to the results when $\mathrm{CC}$ was used as an activating reagent (Scheme 4, Table 4, entries 5,8$)$. The system of DCMT/DMSO was efficient for aliphatic amides (Scheme 4, Table 4, entries 10-13).

Based on these experiments, a possible mechanism $[6,23,25]$ is shown in Scheme 5. Intermediate 1 reacted with amides by two pathways. When the reaction of benzamide and $\mathrm{CC}$-activated DMSO was carried out in chloroform, $S, S$-dimethyl- $N$-benzoylsulfilimine (4) was isolated as a major product, most probably formed by the attack of the amide on the sulfonium ion $\mathbf{1}$. When the reaction is carried out in toluene, intermediate $\mathbf{1}$ decomposes into intermediate $\mathbf{2}$. Thioether $\mathbf{3}$ is formed by the addition of the amide to intermediate 2. $\mathrm{N}$-(Methylthiomethyl)octanamide (40\% yield) was isolated when octanamide was treated with DCMT in DMSO. Similarly, $N$-(1-(methylthio)-2-oxo-2phenylethyl)benzamide (30\% yield) was isolated when benzamide reacted with DCMT and 2-(methylsulfinyl)-1-phenylethanone. Thioether $\mathbf{3}$ is a good nucleophile and capable to substitute the chloride of CC or DCMT to generate sulfonium salt $\mathbf{5}$.<smiles>NC(=O)c1ccccc1</smiles>

Scheme 3: Synthesis of $N, N^{\prime}$-methylenedibenzamide using DCMTactivated DMSO.

Table 3: Optimization studies for the synthesis of $N, N^{\prime}$-methylenedibenzamide using DCMT-activated DMSO ${ }^{\mathrm{a}}$.

\begin{tabular}{lllll} 
Entry & Solvent & Temp $\left({ }^{\circ} \mathrm{C}\right)$ & $\mathrm{t}(\mathrm{h})$ & Yield $^{(\%)^{\mathrm{a}}}$ \\
\hline 1 & $\mathrm{CH}_{3} \mathrm{CN}$ & Reflux & 24 & 0 \\
2 & $\mathrm{CHCl}_{3}$ & Reflux & 24 & 0 \\
3 & 1,2-Dichloroethane & Reflux & 24 & 0 \\
4 & Dioxane & 100 & 3 & 75 \\
5 & Xylene & 100 & 3 & 70 \\
6 & DMSO & 100 & 1 & 75 \\
\hline
\end{tabular}

${ }^{\mathrm{a}} 1.0$ equiv amide, 1.5 equiv DCMT, dry DMSO $(4.0 \mathrm{~mL}), 100^{\circ} \mathrm{C} .{ }^{\mathrm{b}}$ Isolated yield.
The amide substitutes the thioether of 5 to form methylenebisamides 6.

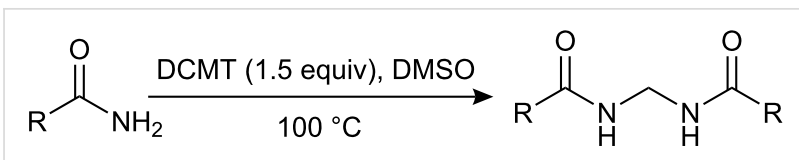

Scheme 4: Synthesis of $N, N^{\prime}-$ methylenebisamide using DCMT-activated DMSO.

Table 4: Scope of the synthesis of $N, N^{\prime}$-methylenebisamide using DCMT-activated DMSOa.

\begin{tabular}{llll} 
Entry & $\mathrm{R}$ & $\mathrm{t}(\mathrm{h})$ & ${\text { Yield }(\%)^{\mathrm{b}}}^{2}$ \\
\hline 1 & $\mathrm{Ph}$ & 1 & 75 \\
2 & $4-\mathrm{CH}_{3} \mathrm{C}_{6} \mathrm{H}_{4}$ & 1 & 77 \\
3 & $4-\mathrm{MeOC}_{6} \mathrm{H}_{4}$ & 1 & 70 \\
4 & $2-\mathrm{MeOC}_{6} \mathrm{H}_{4}$ & 0.5 & 52 \\
5 & $3,5-\left(\mathrm{MeO}_{2} \mathrm{C}_{6} \mathrm{H}_{3}\right.$ & $3^{\mathrm{C}}$ & 50 \\
6 & $4-\mathrm{ClC}_{6} \mathrm{H}_{4}$ & 1 & 88 \\
7 & $3-\mathrm{ClC}_{6} \mathrm{H}_{4}$ & 1.5 & 54 \\
8 & $4-\mathrm{NO}_{2} \mathrm{C}_{6} \mathrm{H}_{4}$ & 3 & 28 \\
9 & $\mathrm{PhCH}^{\mathrm{CH}}$ & 1 & 55 \\
10 & $\mathrm{PhCH}_{2}$ & 4 & 45 \\
11 & $\mathrm{PhOCH}_{2}$ & 2 & 62 \\
12 & $\left(\mathrm{CH}_{3}\right)_{3} \mathrm{C}$ & 1 & 60 \\
13 & $\mathrm{CH}_{3}\left(\mathrm{CH}_{2}\right)_{5} \mathrm{CH}_{2}$ & 3 & $20^{\mathrm{d}}$ \\
\hline
\end{tabular}

a 1.0 equiv amide, 1.5 equiv DCMT, dry DMSO $(4.0 \mathrm{~mL}), 100^{\circ} \mathrm{C} .{ }^{\mathrm{b}}$ Isolated yield; ${ }^{\mathrm{C}}$ The reaction performed at $70{ }^{\circ} \mathrm{C}$;

$\mathrm{d} N$-(Methylthiomethyl)octanamide ( $40 \%$ yield) as major product.<smiles>[X]c1nc(Cl)nc(Cl)n1</smiles>

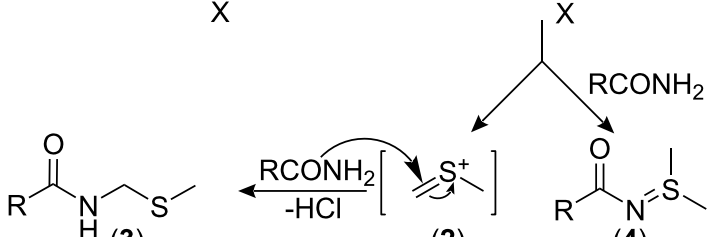
(3)

(2)

(4)

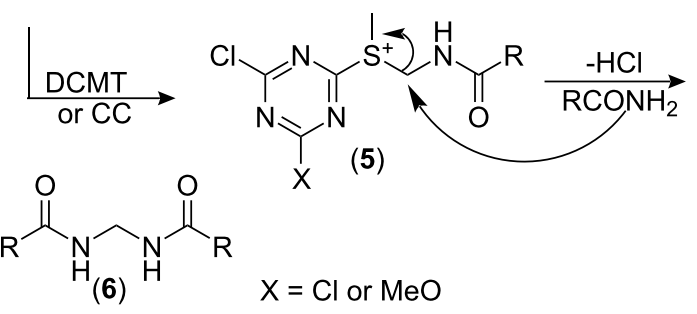

Scheme 5: Plausible reaction mechanism of amide with CC- or DCMT-activated DMSO. 


\section{Conclusion}

In conclusion, we have developed a simple and efficient procedure to produce methylenebisamides in good yield via the reaction of amides with CC- or DCMT-activated DMSO. The procedure reported herein is operationally simple, and requires inexpensive and commercially available reagents. A plausible mechanism of the reaction which involves two sulfonium salt intermediates was proposed and supported by the experiments.

\section{Experimental}

All chemicals were obtained from commercial sources or prepared according to standard methods [24]. All chemicals and solvents used in the reactions were dried by standard procedures prior to use. IR spectra were recorded on a Bio-Rad Exalibur FTS3000 spectrometer. The ${ }^{1} \mathrm{H}$ NMR (500 MHz) and ${ }^{13} \mathrm{C}$ NMR (125 MHz) were recorded on a Varian Oxford 500 spectrometer. Chemical shifts $(\delta)$ are reported relative to TMS $\left({ }^{1} \mathrm{H}\right)$ in DMSO- $d_{6}$ or $\mathrm{CDCl}_{3}\left({ }^{13} \mathrm{C}\right)$. Mass spectra were obtained using an LCQ Advantage MAX ion trap mass spectrometer equipped with electrospray ionization (ESI) ion source or a Thermo Finnigan TRACE-DSQ spectrometer. Elemental analyses for $\mathrm{C}, \mathrm{H}$ and $\mathrm{N}$ were performed on a Yanaco CHNCORNER MF-3 elemental analyzer, and the analytical results were within $\pm 0.4 \%$ of the theoretical values.

\section{Typical experimental procedure}

$N, N^{\prime}$-Methylenedibenzamide (Table 2, entry 1 )

A mixture of amide (121.4 mg, $1.0 \mathrm{mmol}, 1$ equiv), CC (222 $\mathrm{mg}, 1.2 \mathrm{mmol}, 1.2$ equiv) and dry DMSO (0.5 mL, $7.0 \mathrm{mmol}$, 7.0 equiv) in dry toluene $(8.0 \mathrm{~mL})$ was stirred for $30 \mathrm{~min}$ at room temperature. The reaction temperature was then kept at 70 ${ }^{\circ} \mathrm{C}$ for $1.5 \mathrm{~h}$ until completion. The mixture was neutralized with saturated aqueous $\mathrm{NaHCO}_{3}(20 \mathrm{~mL})$, then extracted with EtOAc $(3 \times 20 \mathrm{~mL})$. The extract was washed with brine $(4 \times 15$ $\mathrm{mL})$, dried over anhydrous $\mathrm{Na}_{2} \mathrm{SO}_{4}$. The solvent was concentrated in vacuo to give the crude product, which was further purified by silica gel column chromatography $(\mathrm{PE} / \mathrm{EA}=1 / 1)$ to afford $N, N^{\prime}$-methylenedibenzamide $(90.1 \mathrm{mg}, 71 \%$ yield).

\section{$N, N^{\prime}$-Methylenedibenzamide (Table 4, entry 1 )}

A mixture of amide (121.4 mg, $1.0 \mathrm{mmol}, 1$ equiv) and DCMT (270 mg, $1.5 \mathrm{mmol}, 1.5$ equiv) in dry DMSO (4.0 mL) was stirred at $100{ }^{\circ} \mathrm{C}$ and monitored by TLC until completion (1.0 h). The working up was similar to Table 2 , entry 1 (95.3 mg, $75 \%$ yield).

\section{Supporting Information}

\section{Supporting Information File 1}

Experimental part

[http://www.beilstein-journals.org/bjoc/content/

supplementary/1860-5397-4-51-S1.doc]

\section{Supporting Information File 2}

NMR spectra of new compounds

[http://www.beilstein-journals.org/bjoc/content/

supplementary/1860-5397-4-51-S2.doc]

\section{Acknowledgments}

We thank NSFC (20572078) and NBU Fund (XK200465 and SS2004031) for financial support.

\section{References}

1. Pfitzner, K. E.; Moffatt, J. G. J. Am. Chem. Soc. 1965, 87, 5661-5670. doi:10.1021/ja00952a026

2. Lerch, U.; Moffatt, J. G. J. Org. Chem. 1971, 36, 3861-3869. doi:10.1021/jo00824a004

3. Albright, J. D.; Goldman, L. J. Am. Chem. Soc. 1965, 87, 4214-4216. doi:10.1021/ja01096a055

4. Hiraki, Y.; Kamiya, M.; Tanikaga, R.; Ono, N.; Kaji, A. Bull. Chem. Soc. Jpn. 1977, 50, 447-452. doi:10.1246/bcsj.50.447

5. Harris, T. D.; Boekelheide, V. J. Org. Chem. 1976, 41, 2770-2772. doi:10.1021/jo00878a028

6. Varkey, T. E.; Whitfield, G. F.; Swern, D. J. Org. Chem. 1974, 39, 3365-3372. doi:10.1021/jo00937a013

7. Claus, P.; Vycudilik, W. Tetrahedron Lett. 1968, 9, 3607-3610. doi:10.1016/S0040-4039(00)75512-2

8. De Lucchi, O.; Miotti, U.; Modena, G. Org. React. 1991, 40, 157-405.

9. Epstein, W. W.; Sweat, F. W. Chem. Rev. 1967, 67, 247-260. doi:10.1021/cr60247a001

10. Sun, L.; Pei, G.; Niu, H.; Wang, Q.; Li, C. Synthesis 2008, in press.

11. Sun, L.; Pei, G.; Li, C. Synthesis 2008, in press.

12. Albright, J. D. J. Org. Chem. 1974, 39, 1977-1979. doi:10.1021/jo00927a054

13. Blotny, G. Tetrahedron 2006, 62, 9507-9522. doi:10.1016/j.tet.2006.07.039

14. Giacomelli, G.; Porcheddu, A.; Luca, L. D. Curr. Org. Chem. 2004, 8, 1497-1519. doi:10.2174/1385272043369845

15. Alemán, C.; Puiggali, J. J. Org. Chem. 1995, 60, 910-924. doi:10.1021/jo00109a023

16. Pallai, P. V.; Struthers, R. S.; Goodman, M.; Moroder, L.; Wunsch, E.; Vale, W. Biochemistry 1985, 24, 1933-1941. doi:10.1021/bi00329a020

17. Rodriguez, M.; Dubreuil, P.; Bali, J.-P.; Martinez, J. J. Med. Chem. 1987, 30, 758-763. doi:10.1021/jm00388a002

18. Fernández, A. H.; Alvarez, R. M.; Abajo, T. M. Synthesis 1996, 1299-1301. doi:10.1055/s-1996-4385

19. Gilbert, E. E. Synthesis 1972, 30-32. doi:10.1055/s-1972-21820

20. Brian, R. C.; Lamberton, A. H. J. Chem. Soc. 1949, 1633-1635. doi:10.1039/jr9490001633

21. Sauer, C. W.; Bruni, R. J. J. Am. Chem. Soc. 1955, 77, 2559-2560. doi:10.1021/ja01614a064 
22. Magat, E. E.; Faris, B. F.; Reith, J. E.; Salisbury, L. F. J. Am. Chem. Soc. 1951, 73, 1028-1031. doi:10.1021/ja01147a042

23. Bochkareva, N. N.; Trub, E. P. J. Gen. Chem. USSR 1984, 54, $619-625$

24. Ortéga, F.; Bastide, J. Bioorg. Chem. 1997, 25, 261-274. doi:10.1006/bioo.1997.1071

25. Kise, H.; Whitfield, G. F.; Swern, D. J. Org. Chem. 1972, 37, 1121-1125. doi:10.1021/jo00973a010

\section{License and Terms}

This is an Open Access article under the terms of the Creative Commons Attribution License

(http://creativecommons.org/licenses/by/2.0), which permits unrestricted use, distribution, and reproduction in any medium, provided the original work is properly cited.

The license is subject to the Beilstein Journal of Organic Chemistry terms and conditions:

(http://www.beilstein-journals.org/bjoc)

The definitive version of this article is the electronic one which can be found at: doi:10.3762/bjoc. 4.51 